\title{
Phenotypic Characterization of a Human Immortalized Cranial Periosteal Cell Line
}

\author{
Dorothea Alexander Regina Biller Melanie Rieger Nina Ardjomandi \\ Siegmar Reinert \\ Department of Oral and Maxillofacial Surgery, University Hospital of Tübingen, Tübingen, Germany
}

\section{Key Words}

Cranial periosteal cells - SV40 immortalization - CD146 expression - TERT expression • Mineralization

\begin{abstract}
Background/Aims: Human cell material for basic research work is limited due to restricted patient numbers and occurring cell senescence during prolonged in vitro cell cultivation. In the present study, we established for the first time a human immortalized cranial periosteal cell line and characterized its phenotype in detail in comparison to that of parental cells. Methods: For this purpose, human primary cranial periosteal cells were stably transduced with the large T antigen CDNA from polyomavirus SV40 (TAg cells). Results: The functional activity of the large $T$ antigen was demonstrated by human telomerase gene expression. Whereas TAg cells maintained long-term cell proliferation, immortalization did not compromise their osteogenic differentiation potential. In contrast, TAg cells showed an earlier and stronger mineralization compared to parental cells. Among the analysed stem cell surface markers, CD146 and MSCA1 (mesenchymal stem cell antigen-1) were shown to be elevated in Tag cells. Gene expression analyses revealed in general higher constitutive m-RNA levels of key factors of osteogenesis than in parental cells. Conclusion: We conclude that the herein generated cell line represents a suitable cell source for basic science research studying bone biology, the osteogenesis process or biomaterial tests for bone regeneration purposes.
\end{abstract}

Dorothea Alexander, $\mathrm{PhD}$

KARGER 125
University Hospital of Tübingen, Department of Oral and Maxillofacial Surgery Osianderstr. 2-8, 72076 Tübingen (Germany)

Tel. +49/7071/2982418, E-Mail dorothea.alexander@med.uni-tuebingen.de 


\section{Cellular Physiology Cell Physiol Biochem 2015;35:2244-2254

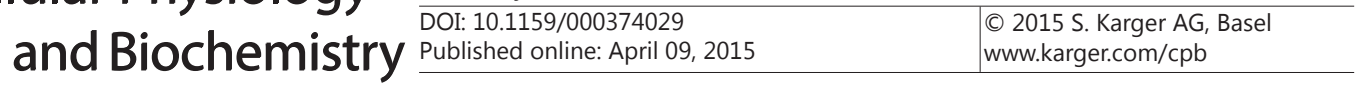 \\ Alexander et al.: Immortalized Cranial Periosteal Cells}

\section{Introduction}

Due to their self-renewal capacity, their ability to differentiate into different cell lineages and their immunosuppressive functions, a wide spectrum of clinical applications of mesenchymal stem cells (MSCs) in the field of regenerative medicine is currently ongoing $[1,2]$. Preliminary observations are promising however, high cell numbers are required resulting in long-term in vitro expansion of MSCs which in turn conflicts with the clinical availability of standardized high quality MSCs.

During long-term cultivation the cell morphology, expression of surface markers, proliferation and differentiation potential of primary cells are strongly affected [3-5]. Furthermore, immunosuppressive effects of MSCs could be impaired by the altered secretory phenotype of senescent cells. By releasing pro-inflammatory cytokines, senescent cells are thought to promote tumor progression in their close environment [6].

Senescent cells remain metabolically active, but they show decreased population doubling times and get an enlarged flat cell morphology as firstly described in the 1960s by Hayflick. In contrast, pluripotent and embryonic stem cells show unlimited self-renewal potential without any signs of replicative senescence [7].

Further efforts in the field of basic and material science should be done to ensure the success of regenerative MSC applications by elucidating key factors/stages of the different differentiation processes and required key properties of biomaterials. For in vitro and in vivo studies, large numbers of cells from early passages are required, giving the limitation for the basic research work using primary cells [8].

In this study, we generated an immortalized periosteal cell line and investigated its phenotypic and functional properties in comparison to the parental cell population. The purpose of this work was to create a basis for the in vitro evaluation of periosteal cell biology, bone formation and for testing of biomaterials using a cell line which maintains long-term cell proliferation without compromising its osteogenic differentiation potential.

\section{Materials and Methods}

\section{Cell material}

A human cranial periosteum biopsy was obtained during routine oral and maxillofacial surgery after obtaining written informed consent of the patient. The sample from one healthy donor (multiple fractures after trauma) was included in this study in accordance with the local ethical committee (Ethik-Kommission der Medizinischen Fakultät Tübingen, approval number 534/2013B01). After breaking down the periosteal tissue followed by a main digestion step using type XI collagenase $(1500 \mathrm{U} / \mathrm{ml}$, Sigma-Aldrich, Steinheim, Germany) for $90 \mathrm{~min}$, the cells were plated into $75 \mathrm{~cm}^{2}$ culture flasks. For cell expansion, cells were cultured in DMEM/F-12 (Invitrogen-BioSource Europe, Nivelles, Belgium) containing 10\% FCS (Sigma-Aldrich, Steinheim, Germany) and 1\% fungicide and penicillin/streptomycin (Biochrom, Berlin, Germany). DMEMcultured cells were expanded and passaged using trypsin-versene EDTA (1x, Lonza, Basel, Schweiz) up to the second passage, then cryo-preserved and sent on dry ice to Sirion Biotech (Martinsried, Germany) for lentiviral transduction with the large SV40 T antigen.

\section{Analysis of the cell morphology and population doubling times}

In order to determine population doubling times of TAg cells ( $\mathrm{n}=4$ independent samples measured in triplicates) in comparison to the parental cells ( $n=2$ independent samples measured in triplicates), they were seeded at a defined cell density and counted after detachment from culture plates and subsequent staining by Trypan blue. The individual constant for each passage was taken into consideration and calculated according the following formula:

$$
N t=N o \times e^{\mathrm{kt}} \rightarrow k=\frac{\ln \left(\frac{N t^{\prime}}{N_{O}}\right)}{t}
$$

whereby: $\mathrm{Nt}=$ cell number (as counted using the Neubauer counting chamber) at time $\mathrm{t}$; No = cell number at time $0 ; \mathrm{k}=$ constant; $\mathrm{t}=$ number of days in culture, were included in the calculation. 


\section{Cellular Physiology Cell Physiol Biochem 2015;35:2244-2254 \begin{tabular}{ll|l} 
and Biochemistry $10.1159 / 000374029$ & Published online: April 09, 2015 & $\begin{array}{l}\text { O 2015 S. Karger AG, Basel } \\
\text { www.karger.com/cpb }\end{array}$ \\
\cline { 2 - 3 }
\end{tabular} \\ Alexander et al.: Immortalized Cranial Periosteal Cells}

Table 1. PDT in days (mean \pm STD, primary cells $n=2$, TAg cells $n=4$ ) during in vitro passaging of immortalized versus parental cells (pr.)

\begin{tabular}{llll}
\hline Passage & Primary cells & TAg cells & Sample size \\
\hline 7 & $3.70 \pm 0.48$ & $9.60 \pm 2.29$ & pr. 2; TAg 4 \\
8 & $1.13 \pm 0.02$ & $25.34 \pm 8.88$ & pr. 2; TAg 4 \\
9 & $1.24 \pm 0.04$ & $12.34 \pm 3.09$ & pr. 2; TAg 4 \\
10 & $1.25 \pm 0.12$ & $31.85 \pm 10.49$ & pr. 2; TAg 4 \\
\hline
\end{tabular}

On the basis of an expected exponential cell growth, the population doubling time ( $\left.\mathrm{t}^{\prime}\right)$ was calculated according following formula:

$$
t^{\prime}=\frac{\ln \left(\frac{N t^{\prime}}{N o}\right)}{k}
$$

whereby: $\mathrm{Nt}^{\prime}=2 \mathrm{x}$ No and $\mathrm{t}^{\prime}=\ln 2 / \mathrm{k}$, is.

The obtained mean values for the population doubling times are summarized in Table 1.

For the visualization of the cell morphology, we fixed the cell monolayers with $3.7 \%$ formaldehyde/ PBS for 10 min at RT. After washing, cells were lysed with PBS/0.1\% Triton x 100 for 15 min at RT by shaking. After two additional washing steps with PBS, cells were stained with Alexa Fluor 488 phalloidin (Invitrogen Molecular Probes, Darmstadt, Germany, 1:40 diluted) for $20 \mathrm{~min}$ at RT in the dark. Cell nuclei were additionally stained with DAPI (Sigma-Aldrich, Munich, Germany, 1:1000 diluted) for $10 \mathrm{~min}$ at RT protected from light. The photographic documentation was carried out using the Observer.Z1 with apotome technique (Zeiss, Oberkochen, Germany).

\section{Lentiviral transduction of primary cranial periosteal cells}

Primary cranial periosteal cells ( 8 aliquots of $5.0 \times 10^{6}$ cells) of the second passage were sent to Sirion Biotech for lentiviral transfection with the vector Lenti_pCDH-CMV-LTtsA58-EF1-Neo (replication-deficient, self-inactivating, 3rd generation lentiviral vector). The expressed transgene is the large T antigen (LTtsA58) cDNA of the polyomavirus SV40. 72 hours after transduction, selection was started with G418 $(0.5 \mathrm{mg} / \mathrm{ml})$. Cells were grown for 10 days under selective pressure and were then cryo-preserved. For maintenance of immortalization cells were grown in the presence of $0.25 \mathrm{mg} / \mathrm{ml} \mathrm{G418}$ at $37^{\circ} \mathrm{C}$ and $5 \% \mathrm{CO}_{2}$. Despite the fact that the involved company intended to carry out a conditional immortalization (postulating the maintenance of immortalization at $33^{\circ} \mathrm{C}$ and the maintenance of the primary phenotype at $37^{\circ} \mathrm{C}$ ) the large SV40 $\mathrm{T}$ antigen was expressed at comparative high levels by the TAg cells regardless of the culture temperature. In favor of better comparability, cell culturing was carried out uniformly at $37^{\circ} \mathrm{C}$ for primary and immortalized cells.

\section{Osteogenic differentiation experiments}

DMEM-cultured primary and immortalized periosteal cells ( $4 \times 10^{4} / 3 \times 10^{4}$ cells per well in 6-well plates) were treated with osteogenic medium (ob - DMEM/F12 containing 10\% FCS, 10 mM $\beta$-glycerophosphate, $100 \mu \mathrm{M}$ L-ascorbic acid 2-phosphate and $4 \mu \mathrm{M}$ dexamethasone, Sigma-Aldrich, Munich, Germany) for the duration indicated in the Figures. The medium was replaced three times per week. Untreated cells that were cultivated without any osteogenic compounds for the same time period served as undifferentiated controls (co).

Western blot analysis of the SV40 large T antigen expression in TAg cells

After 2-3 days of culture, TAg cells were harvested on ice and centrifuged for $7 \mathrm{~min}$ at $4^{\circ} \mathrm{C}$ and 1400 rpm. Cell pellets ( 1 x $10^{6}$ cells) were dissolved in $60 \mu$ lysis buffer (1\% NP40; $150 \mathrm{mM} \mathrm{NaCl} ; 50 \mathrm{mM}$ Tris/ HCL, pH 8.0 plus protease inhibitors (Complete, EDTA-free, Roche, Mannheim, Germany)) and incubated overnight at $-70^{\circ} \mathrm{C}$. After centrifugation of cell debris $\left(15000 \mathrm{~g}\right.$, at $4^{\circ} \mathrm{C}$ for $\left.20 \mathrm{~min}\right)$ protein concentrations of the supernatants were measured using a colorimetric assay (RD DC Protein Assay, Bio- Rad Laboratories, Munich, Germany) according to the manufacturer's instructions. After addition of reducing Laemmli sample buffer (1:3), a total of $100 \mu \mathrm{g}$ of cell lysate were denatured for $5 \mathrm{~min}$ at $95^{\circ} \mathrm{C}$, separated by SDS-PAGE (8\%) and transferred onto nitrocellulose membranes. After washing and blocking the membranes with PBS $/ 0.1 \%$ 


\section{Cellular Physiology Cell Physiol Biochem 2015;35:2244-2254 \begin{tabular}{l|l|l}
\hline DOI: 10.1159/000374029 & C 2015 S. Karger AG, Basel
\end{tabular} and Biochemistry $\frac{\text { Published online: April 09, } 2015}{\text { Alexander et al.: Immortalized Cranial Periosteal Cells }}$}

Tween 20/5\% milk powder, the monoclonal mouse anti-SV40 T antigen specific primary antibodies were incubated with the membranes overnight at $4{ }^{\circ} \mathrm{C}$ (1:500 diluted; Biozol, Eching, Germany). Binding of the primary antibodies was detected with peroxidase-conjugated goat anti-mouse secondary antibodies (Santa Cruz Biotech, Heidelberg, Germany) and visualized by the enhanced chemiluminescence method (GE Healthcare, Freiburg, Germany). As loading controls, human GAPDH (37 KDa) protein expression was detected in the same lysates after membrane stripping in stripping buffer (PBS, $100 \mathrm{mM} ß$-mercaptoethanol, $2 \%$ SDS, $62.5 \mathrm{mM}$ Tris $\mathrm{pH} 6.8$ ) at $50^{\circ} \mathrm{C}$ for $30 \mathrm{~min}$. After two additional washing steps, membranes were incubated with mouse anti-GAPDH specific antibodies overnight at $4^{\circ} \mathrm{C}$ (1:5000 diluted; Abcam, Cambridge, UK). For the detection and visualization of the GAPDH protein levels, the same procedure was chosen as described above for SV40 T antigen detection.

\section{Flow cytometry analysis of cell surface marker expression}

Primary and immortalized TAg cells ( $\mathrm{n}=3$ independent samples for each cell type) were detached from culture dishes, centrifuged (1400 rpm, $7 \mathrm{~min}$ at $4^{\circ} \mathrm{C}$ ), resuspended in $50 \mu \mathrm{l}$ of $10 \%$ Gamunex (human immune globulin solution, Talecris Biotherapeutics GmBH, Frankfurt, Germany) and incubated for 15 $\min$ at $4^{\circ} \mathrm{C}$. In the presence of FACS buffer (PBS, $0.1 \%$ BSA, $0.1 \%$ sodium azide), the cells were incubated with specific phycoerythrin (PE)-labeled mouse anti-human CD45, CD73, CD90, CD166 (BD Biosciences, Heidelberg, Germany), CD44 (Exbio, Praha, Czech Republic), CD105 (AbD Serotec, Bio-Rad Laboratories, Munich, Germany) and MSCA-1, CD31, CD34 and CD146 (Miltenyi Biotec, Mönchengladbach, Germany) for $15 \mathrm{~min}$ at $4^{\circ} \mathrm{C}$. The cells were centrifuged $\left(1400 \mathrm{rpm}, 7 \mathrm{~min}\right.$ at $\left.4^{\circ} \mathrm{C}\right)$, washed twice with FACS buffer and resuspended in $200 \mu \mathrm{l}$ of FACS buffer for flow cytometric analysis. The measurements were carried out using the guava easyCyte 6-2L flow cytometer (Merck Millipore, Schwalbach, Germany). Cells incubated with polyclonal goat anti-mouse immunoglobulins served as negative isotype controls. For data evaluation, the guavaSoft 2.2.3 (InCyte 2.2.2) software was used.

\section{Detection of cell mineralization by fluorescent OsteoImage staining}

Whereas the mineralization potential of periosteal cells is a crucial function, we detected in vitro cell mineralization by Alizarin and OsteoImage stainings. Based on the fact that the specificity for hydroxyapatite of both stains has been controversially discussed $[9,10]$, we used the fluorescent OsteoImage mineralization assay (Merck Millipore, Schwalbach, Germany), which promised to be more specific for inorganic hydroxyapatite. Undifferentiated and osteogenically induced primary and immortalized cells were fixed with zinc-formaline for $20 \mathrm{~min}$. After three washing steps, cells were incubated with diluted staining reagent in the dark for $30 \mathrm{~min}$, following the manufacturer's instructions. After washing, the stained cells were visualized using the Observer.Z1 microscope (Zeiss, Oberkochen, Germany).

Gene expression analysis in primary and immortalized cells

RNA isolation from primary and immortalized periosteal cells ( $\mathrm{n}=3$ independent samples for each cell type) was carried out using the RNeasy Micro kit (Qiagen, Hilden, Germany) following the manufacturer's instructions. After photometrical measurements and quantification of isolated RNA (GeneQuant Pro; GE Healthcare, Freiburg, Germany), $0.5 \mu \mathrm{g}$ of RNA was used for cDNA synthesis using the Advantage RT-for-PCR kit (Clontech, Saint-German-en-Laye, France) following the manufacturer's instructions.

mRNA expression levels of Runx-2, alkaline phosphatase (AP), osteocalcin (OCN) and type I collagen ( $\alpha 1$-chain) were quantified using the LightCycler System (Roche, Mannheim, Germany), the commercial primer kits (Search LC, Heidelberg, Germany) and the DNA Master Sybr Green 1 (Roche Diagnostics GmbH, Mannheim, Germany) for 40 cycles. The detected gene expression levels were normalized to those of the housekeeping gene glycerinaldehyde 3-phosphate dehydrogenase (GAPDH). The ratios of target genes to GAPDH expression levels in untreated and osteogenically induced samples during different time points (day 3, 10 and 15) of osteogenesis are illustrated in Fig 6.

\section{Statistical analysis}

The data are expressed as the mean \pm standard deviation. For the statistical analysis, student's t-test was used. A p-value $<0.05$ was considered significant.

\section{KARGER}


Results

Detection of the SV40 large T antigen by western blot

SV40 large $\mathrm{T}$ antigen expression was analyzed in whole cell lysates from TAg cells by western blot. Due to the fact that a conditional immortalization was planned, TAg cells were cultivated at temperatures between $33-39^{\circ} \mathrm{C}$. As illustrated in Fig. 1, SV40 large $\mathrm{T}$ antigen protein expression was detected at comparative high levels in all whole cell lysates at the expected size of 80 $\mathrm{kDa}$, irrespective of the culture temperature. As expected, primary parental cells showed no specific signal (as shown in lane 2 of Fig. 1).

Detection of human telomerase (hTERT) by $q-R T-P C R$

Since a high percentage of tumor cells show telomerase expression, we analyzed hTERT gene expression in TAg and parental cells by quantitative RT-PCR. As illustrated in Fig. 2, we detected specific mRNA amplification for hTERT in TAg cells irrespective of the differentiation state (in control and osteogenic-induced cells), as shown in lane 6 and 10 of the Figure. In contrast, primary parental cells did not express hTERT constitutively (as shown in lane 7 and 11).

Cell morphology and population doubling times (PDT)

TAg cells reduced significantly their cell size/cytoplasmic volume as illustrated in Fig. 3. In terms of proliferation, TAg cells (n $=4$ ) showed substantially shorter population doubling times (PDT) in comparison to those of primary parental cells $(\mathrm{n}=2)$ as listed in Table 1. Since primary periosteal cells stopped to proliferate, we finalized the PDT calculations after passage 11 of cell culture.

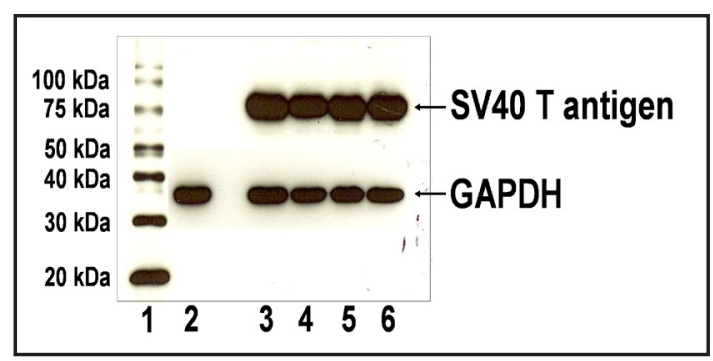

Fig. 1. Detection of the SV40 large T antigen expression in TAg cells in relation to the culture temperature by western blotting. 1 - molecular marker; 2 - primary cell lysates; 3 - TAg cell lysates from cells cultured at $33^{\circ} \mathrm{C} ; 4-\mathrm{TAg}$ cell lysates from cells cultured at $37^{\circ} \mathrm{C} ; 5$ - TAg cell lysates from cells cultured at $38^{\circ} \mathrm{C} ; 6-\mathrm{TAg}$ cell lysates from cells cultured at $39^{\circ} \mathrm{C}$. Specific bands for the SV40 large $\mathrm{T}$ antigen were detected at approximately $80 \mathrm{kDa}$. As loading controls, human GAPDH (37 kDa) protein expression was detected in the same lysates after membrane stripping.

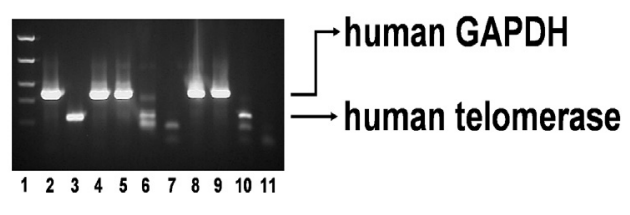

Fig. 2. Detection of human telomerase (hTERT) by quantitative PCR. 1 - base pair ladder; 2 - positive control for human GAPDH gene expression; 3 - positive control for human TERT gene expression; 4 - human GAPDH expression in untreated TAg cells; 5 - human GAPDH expression in untreated primary periosteal cells; 6 - human TERT expression in untreated TAg cells; 7 - human TERT expression in untreated primary periosteal cells; 8 - human GAPDH expression in osteogenically induced TAg cells; 9 human GAPDH expression in osteogenically induced primary periosteal cells; 10 - human TERT expression in osteogenically induced TAg cells; 11 - human TERT expression in osteogenically induced primary periosteal cells.

Flow cytometric analysis of cell surface marker expression

In order to compare the phenotype of immortalized TAg cells with that of primary cells, we analyzed different mesenchymal stem cell markers, endothelial (CD31), pericytes (CD146), leucocyte (CD45) and mesenchymal stem cell antigen (MSCA-1) cell surface expression. Representative histograms are illustrated in Fig. 4.

For flow cytometric analyses cells were cultivated for 10 days. As summarized in Table 2 , TAg and primary cells showed similar expression patterns except the CD146 and MSCA-1 expression. Primary and immortalized cells were positive for CD44, CD73, CD90, CD105 and CD166 and negative for CD31, CD45 and showed low expression of CD34. 
Fig. 3. Comparison of cell morphology of TAg (immortalized) and primary cells using fluorescence microscopy (green: Phalloidin - staining of the cytoskeleton, blue: DAPI - staining of the cell nuclei) at day 3, 5 and 7 after cell seeding. TAg cells show reduced cell size and a more roundish shape in comparison to the parental cells, considering the $200 \mu \mathrm{m}$ scale bar. At day 7, a higher cell density was achieved by TAg cells.
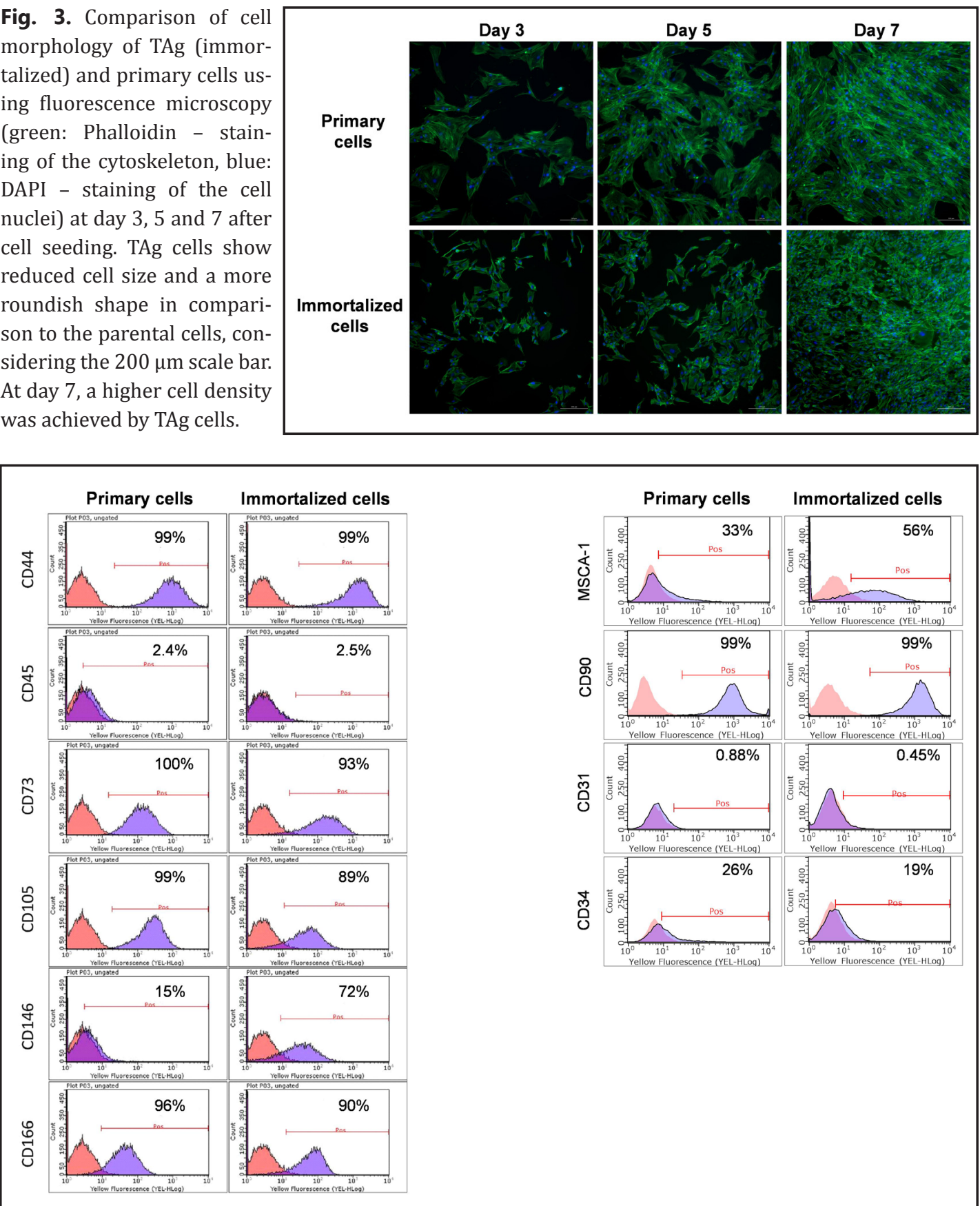

Fig. 4. Cell surface marker expression by flow cytometry. On the left panel of the Figure, representative histograms for CD44, CD45, CD73, CD105, CD146, CD166 and on the right panel for MSCA-1 (mesenchymal stem cell antigen-1), CD90, CD31, and CD34 expression by TAg (immortalized) and primary cells are illustrated.

Interestingly, TAg cells revealed in comparison to primary cells a significant higher surface expression of the pericyte cell surface marker CD146 (percentage of positive cells $72.41 \pm 6.90$ versus $14.91 \pm 8.94, \mathrm{p}<0.001$ ).

In previous studies, we identified the mesenchymal stem cell antigen-1 (MSCA-1) to specifically hallmark the osteogenic progenitor subpopulation within the whole cell population derived from jaw periosteum. Interestingly, whereas the MSCA-1+ cell fraction

\section{KARGER}


Table 2. Percentages of positive primary and TAg cells (mean \pm STD, $n=3$ ) for the listed surface antigens. Significant differences in surface expression between primary and immortalized cells are indicated by the listed p-value

\begin{tabular}{lcccccccccc}
\hline & CD31 & CD34 & CD44 & CD45 & CD73 & CD90 & CD105 & CD146 & CD166 & MSCA-1 \\
\hline Primary & $0.88 \pm$ & $26.33 \pm 1$ & $99.23 \pm 0$. & $2.42 \pm$ & $99.62 \pm 0$. & $98.88 \pm 0$. & $99.25 \pm 0$. & $14.91 \pm$ & $95.53 \pm 2$. & $32.69 \pm 1$ \\
cells & 0.45 & 3.16 & 37 & 1.49 & 15 & 46 & 30 & 8.94 & 55 & 1.61 \\
TAg & $0.45 \pm$ & $18.87 \pm 7$. & $98.65 \pm 0$. & $2.47 \pm$ & $92.68 \pm 5$. & $98.92 \pm 0$. & $89.19 \pm 5$. & $72.41 \pm 6$. & $89.52 \pm 7$. & $56.95 \pm 9$. \\
cells & 0.31 & 85 & 77 & 1.16 & 51 & 38 & 03 & 90 & 19 & 69 \\
p-value & n.s. & n.s. & n.s. & n.s. & n.s. & n.s. & n.s. & $<0.001$ & n.s. & $<0.05$ \\
\hline
\end{tabular}

A
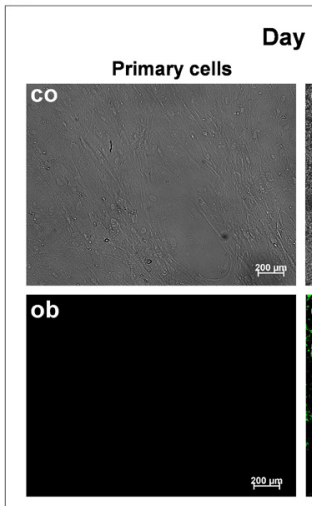

B

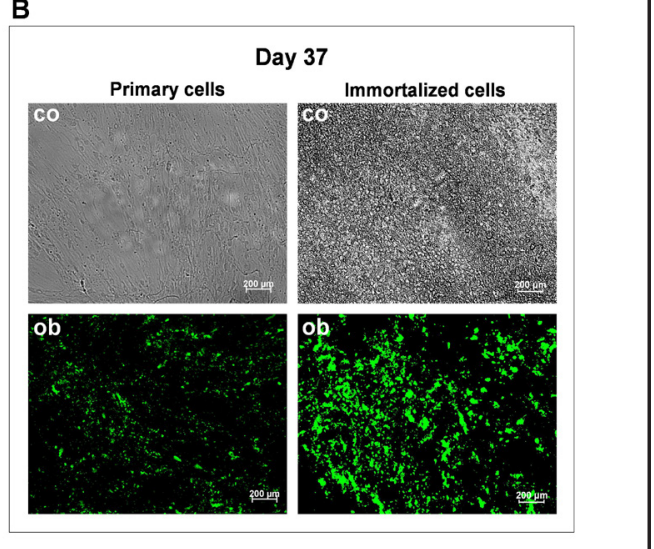

Fig. 5. Fluorescent detection of hydroxyapatite formation in TAg (immortalized) and primary cells by OsteoImage. Representative stainings are illustrated after 15 (A) and 37 (B) days of osteogenic induction (scale bar $-200 \mu \mathrm{m})$. co: untreated cells, ob: osteogenic induced cells.

represents a rare subpopulation of in general up to $10 \%$, primary cranial periosteal cells deriving from this patient were $32.69 \pm 11.61 \%$ positive for MSCA-1. TAg cells showed a significant higher MSCA-1 expression on their surface $(56.95 \pm 9.69 \%, \mathrm{p}<0.05)$.

\section{Analysis of cell mineralization in TAg and parental cells}

In general, we made the observation that TAg cells mineralize earlier and stronger than the respective parental cells. Representative fluorescent stainings are shown in Fig. 5. Whereas primary cells do not mineralize 15 days after osteogenic induction, TAg cells showed clear calcium phosphate precipitates as shown in Fig. 5A by OsteoImage staining. Following osteogenic induction for almost 40 days, primary cells mineralize to a lower extent that the respective immortalized cells (Fig. 5B).

\section{Gene expression analysis of osteogenesis-relevant marker}

In accordance with the earlier and stronger osteogenic capacity observed in TAg cells, gene expression analyses revealed in general higher constitutive m-RNA levels of key factors of osteogenesis than in parental cells. Regarding the gene expression of the transcription factor Runx-2, higher levels were detected in untreated and induced TAg cells at all examined time points reaching significant values firstly after day 15 of osteogenesis (co: $p<0.05$, ob: $p<0.01$ ). At the beginning of the osteogenic differentiation (at day 3 and 10), the tendency of higher expression levels of alkaline phosphatase were detected in TAg cells. However, detected levels reached only after 3 days of osteogenic induction significant values $(\mathrm{p}<$ 0.05). Since alkaline phosphatase represents an early osteogenic factor, osteocalcin is known to characterize the late mineralization phase of differentiation. Osteocalcin m-RNA levels were comparable in immortalized and primary cells at the beginning of osteogenesis (day 3 ) and were shown to be upregulated at later examination time points in TAg cells. However, 


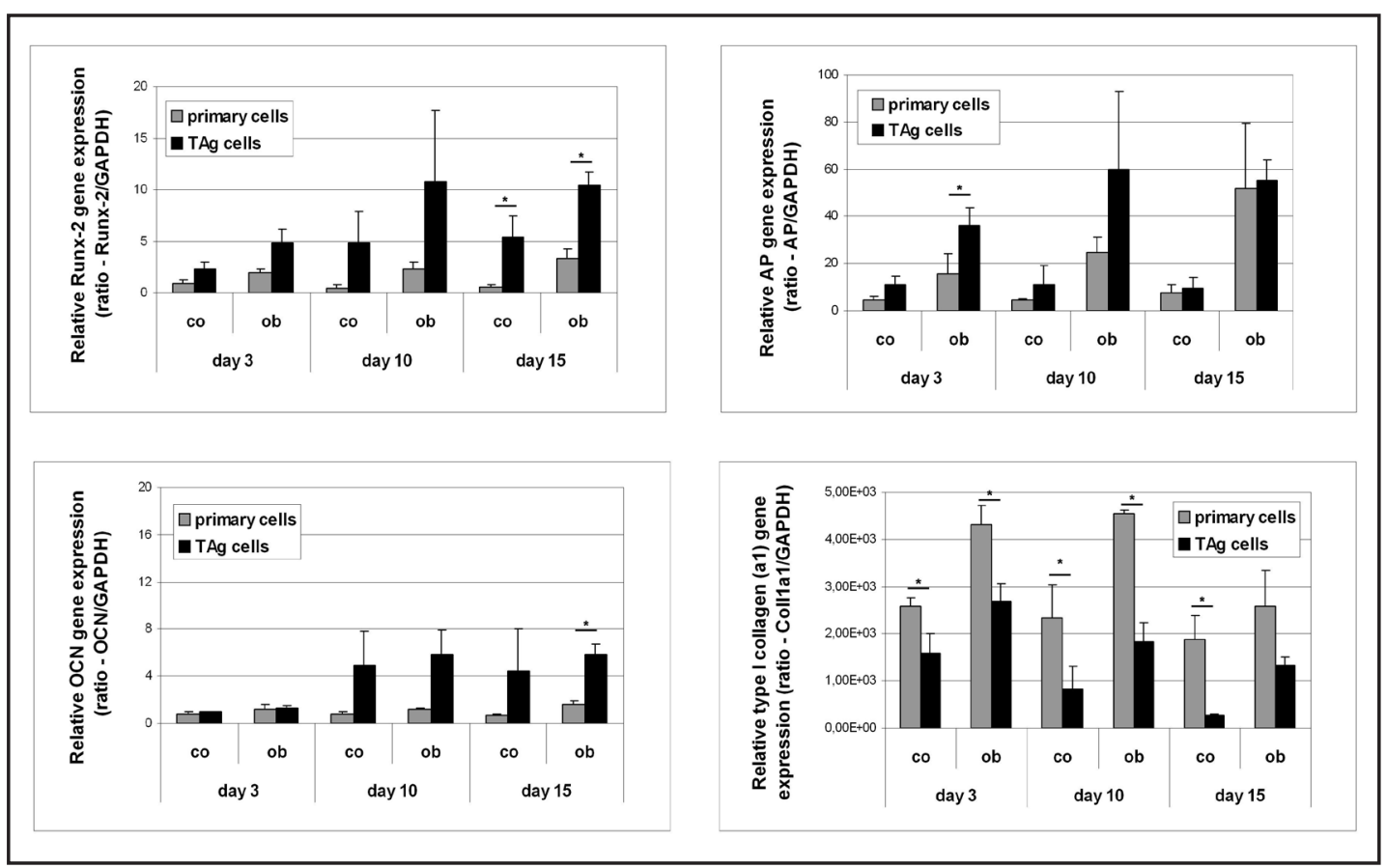

Fig. 6. Gene expression analyses of osteogenesis-relevant markers (Runx-2, AP - alkaline phosphatase, OCN - osteocalcin, Coll1a1 - type I collagen ( $\alpha 1$ - chain)) in TAg and primary cells by quantitative-PCR. The ratios target gene/GAPDH expression in untreated (co) and osteogenically induced (ob) TAg and primary cells are illustrated during different time points of osteogenesis. $\mathrm{p}<0.05$ was considered as significant.

expression differences were significant $(\mathrm{p}<0.01)$ only at day 15 of osteogenesis. Type I collagen ( $\alpha 1$-chain) gene levels were uniformly induced after osteogenic stimulation (ob) in TAg and primary cells. However, significantly higher collagen expression was detected in untreated and osteogenic induced primary cells. A stepwise constitutive decrease in type I collagen expression was observed in immortalized cells (co, day 3 versus day 15: $p<$ $0.05)$, whereas basic m-RNA levels did not significantly alter in parental cells. We detected a similar and significant repression of type I collagen expression at day 15 of osteogenesis (co: $\mathrm{p}<0.01$, ob: $\mathrm{p}<0.05$ ).

\section{Discussion}

Only very limited numbers of human cell lines derived from mesenchymal stem cell population already exist. Thalmeier and co-authors described two human cell lines derived from primary bone marrow cell cultures in 2001 [11].

Immortalized human fetal bone-marrow derived cells were recently described to represent a suitable, safe and effective source for suicide gene delivery in anti-tumor therapeutical approaches, as demonstrated in vitro and in an immunodeficient animal model [12].

For bone biology studies, murine immortalized cell lines derived from the calvaria of newborn mice was currently established $[13,14]$. In the present study, we generated a human immortalized cranial periosteal cell line for the first time. While gaining long-term proliferative capacity and maintaining crucial features of the parental primary cells, we think that this cell line represents a suitable experimental platform for studying periosteal cell biology and bone formation. Better understanding of this process could improve the transfer of periosteal cell therapies into safe and successful clinical applications for bone regeneration. 


\section{Cellular Physiology Cell Physiol Biochem 2015;35:2244-2254

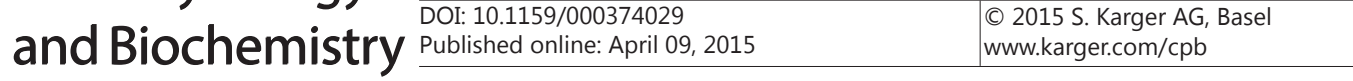 \\ Alexander et al.: Immortalized Cranial Periosteal Cells}

In general, telomerase activity expression is absent in most somatic cells resulting in sustained chromosome end shortening during cell proliferation. This cellular event decreases the replicative potential of primary cells leading to cell senescence or crisis, and in the final step to cell death. A high percentage of tumor and immortalized cells shows telomerase activity [15-18], and it has been suggested that hTERT (representing the protein component of the telomerase) expression may be one of the six key hallmarks associated with cancer development [19]. Yang and co-authors demonstrated that concurrent disruption of p53 expression and ectopic expression of the catalytic subunit of telomerase was sufficient to induce cellular immortalization in 3 of 3 human ovarian surface epithelial cell cultures [20]. Moreover, recent studies suggest that the telomerase subunit telomerase reverse transcriptase (TERT) has novel molecular functions including transcriptional regulation and metabolic reprogramming, as summarized in a recent article focusing the central role of TERT [21] in cancer.

The herein generated immortalized periosteal cell line showed hTERT expression indicating the mode of action of the integrated SV40 large T antigen to escape cell senescence. We expected a differential gene expression of the tumor suppressor gene p53 in TAg and primary cells but we could not detect relevant differences regarding the mRNA levels in both cell types.

In previous studies, we identified the mesenchymal stem cell antigen- 1 as a specific marker for osteogenic progenitors (in general up to 5-10\%) within the heterogeneous cell population derived from the jaw periosteum [22]. Interestingly, 56.28 $\pm 10.25 \%$ of TAg cells were positive for MSCA-1 in relation to the achieved cell density and differentiation state, this giving a reason for the observed better/stronger mineralization capacity of TAg cells compared to the parental cells. Both, the higher proliferative capacity leading in a shorter time to high cell densities required for strong mineralization and the ca. 2 -fold higher content of MSCA-1 positive cells are probably synergistic events leading to the observed higher mineralization potential of TAg cells. Since it was hypothesized that the mesenchymal stem cell antigen probably coincide with the tissue non-specific alkaline phosphatase (TNAP) [23], constitutive higher alkaline phosphatase mRNA levels illustrated in Fig. 6 could confirm the constitutive higher MSCA-1 expression in TAg cells detected by flow cytometry compared to parental cells. Besides the higher expression of alkaline phosphatase on gene and protein level, we detected higher constitutive mRNA levels of runx-2 and osteocalcin in immortalized cells in comparison to the primary periosteal cells they derived from, as illustrated in Fig 6. Based on the fact that immortalized cells are to an extent cancer cells exhibiting abnormal and disorganized extracellular matrix, lower type I collagen expression levels are often detected in immortalized cells [24]. It was therefore unsurprising that immortalized periosteal cells expressed lower levels of type I collagen compared to the primary cells. Although type I collagen represents the basis for the mineralization process and despite the significant lower constitutive type I collagen levels in immortalized cells, the mineralization potential seemed to be stronger than that of parental cells. This can be explained by above mentioned factors including the higher proliferation capacity reaching in a shorter time to high cell densities as well as higher MSCA-1 and osteogenic factor expression.

It has been postulated that mesenchymal cells isolated from different adult tissues/ organs originate from pericytes [25]. As reviewed in Stem Cells last year by Lv and co-authors, there is actually no sole marker that is truly MSC-specific. In this review, the authors made the conclusion that among the published MSC markers, CD146 may be the most appropriate stemness marker, as it is universally detected in the MSC population isolated from various tissues, and enriches cells with clonogenicity and multipotency [26]. MSC progenitors could be prospectively purified from multiple human tissues as CD146+CD34-CD45CD56- pericytes [27]. Pericytes, also known as mural or Rouget cells, are closely associated to endothelial cells and probably fulfil contractile functions in capillaries, are positive for CD146, CD105 and negative for CD31 and CD34 and show differentiation potential into different cell types such as osteoblasts, adipocytes, fibroblasts, smooth muscle cells and macrophages [28]. Since human periosteal tissue is a highly vascularized tissue, and 


\section{Cellular Physiology Cell Physiol Biochem 2015;35:2244-2254 \begin{tabular}{l|l} 
DOI: 10.1159/000374029 2025 & 015 s. Karger AG, Basel
\end{tabular} www.karger.com/cpb

$72.41 \pm 6.9 \%$ of TAg cells were shown to be CD146+ (compared to $15.24 \pm 9.52 \%$ of parental cells), it could be possible that containing pericytes from the primary cell culture were SV40 TAg immortalized. However, due to the fact that not all TAg cells showed to be uniformly CD146 positive, a heterogeneous cell population probably occurs. This is not surprising in particular because the parental cell population was heterogeneous too.

Taken together, we developed a cranial periosteal cell line showing pericytic characteristics and a higher osteogenic potential compared to the parental cell population it derives from. We have created an excellent cell source for further basic research in the field of bone biology and regeneration. It remains to be analysed whether and to what extend the knowledge of the higher and earlier mineralization potential of these cells could be transferred into clinical applications.

\section{Disclosure Statement}

The authors have nothing to disclose.

\section{References}

1 Kramer J, Dazzi F, Dominici M, Schlenke P, Wagner W: Clinical perspectives of mesenchymal stem cells. Stem Cells Int 2012;2012:684827.

2 Dazzi F, Lopes L, Weng L: Mesenchymal stromal cells: a key player in 'innate tolerance'? Immunology 2012;137:206-213.

3 Wagner W, Horn P, Castoldi M, Diehlmann A, Bork S, Saffrich R, Benes V, Blake J, Pfister S, Eckstein V, Ho AD: Replicative senescence of mesenchymal stem cells: a continuous and organized process. PLoS ONE 2008;3:e2213.

4 Bork S, Pfister S, Witt H, Horn P, Korn B, Ho AD, Wagner W: DNA methylation pattern changes upon longterm culture and aging of human mesenchymal stromal cells. Aging Cell 2010;9:54-63.

5 Wagner W: Implications of long-term culture for mesenchymal stem cells: genetic defects or epigenetic regulation? Stem Cell Res Ther 2012;3:54.

6 Davalos AR, Coppe JP, Campisi J, Desprez PY: Senescent cells as a source of inflammatory factors for tumor progression. Cancer Metastasis Rev 2010;29:273-283.

7 Zeng X: Human embryonic stem cells: mechanisms to escape replicative senescence? Stem Cell Rev 2007;3:270-279.

8 Razzouk S, Schoor R: Mesenchymal stem cells and their challenges for bone regeneration and osseointegration. J Periodontol 2012;83:547-550.

9 Bonewald LF, Harris SE, Rosser J, Dallas MR, Dallas SL, Camacho NP, Boyan B, Boskey A: von Kossa staining alone is not sufficient to confirm that mineralization in vitro represents bone formation. Calcif Tissue Int 2003;72:537-547.

10 Wang YH, Liu Y, Maye P, Rowe DW: Examination of mineralized nodule formation in living osteoblastic cultures using fluorescent dyes. Biotechnol Prog 2006;22:1697-1701.

11 Thalmeier K, Meissner P, Moosmann S, Sagebiel S, Wiest I, Huss R: Mesenchymal differentiation and organ distribution of established human stromal cell lines in NOD/SCID mice. Acta Haematol 2001;105:159-165.

12 Lee WY, Zhang T, Lau CP, Wang CC, Chan KM, Li G: Immortalized human fetal bone marrow-derived mesenchymal stromal cell expressing suicide gene for anti-tumor therapy in vitro and in vivo. Cytotherapy 2013;15:1484-1497.

13 Nakamura-Ota M, Hamanaka R, Yano H, Adachi S, Sumiyoshi H, Matsuo N, Yoshioka H: A new murine osteoblastic cell line immortalized with the SV40 large T antigen. Cell Tissue Bank 2014;15:373-380.

14 Wu LA, Feng J, Wang L, Mu YD, Baker A, Donly KJ, Harris SE, MacDougall M, Chen S: Development and characterization of a mouse floxed Bmp2 osteoblast cell line that retains osteoblast genotype and phenotype. Cell Tissue Res 2011;343:545-558. 


\section{Cellular Physiology Cell Physiol Biochem 2015;35:2244-2254

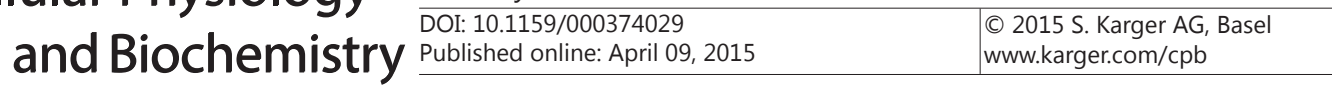 \\ Alexander et al.: Immortalized Cranial Periosteal Cells}

15 Kim NW, Piatyszek MA, Prowse KR, Harley CB, West MD, Ho PL, Coviello GM, Wright WE, Weinrich SL, Shay JW: Specific association of human telomerase activity with immortal cells and cancer. Science 1994;266:2011-2015.

16 Greider CW, Blackburn EH: Telomeres, telomerase and cancer. Sci Am 1996;274:92-97.

17 Shay JW, Bacchetti S: A survey of telomerase activity in human cancer. Eur J Cancer 1997;33:787-791.

18 Cong YS, Wright WE, Shay JW: Human telomerase and its regulation. Microbiol Mol Biol Rev 2002;66:40725 , table.

19 Hanahan D, Weinberg RA: The hallmarks of cancer. Cell 2000;100:57-70.

20 Li NF, Broad S, Lu YJ, Yang JS, Watson R, Hagemann T, Wilbanks G, Jacobs I, Balkwill F, Dafou D, Gayther SA: Human ovarian surface epithelial cells immortalized with hTERT maintain functional pRb and p53 expression. Cell Prolif 2007;40:780-794.

21 Low KC, Tergaonkar V: Telomerase: central regulator of all of the hallmarks of cancer. Trends Biochem Sci 2013;38:426-434.

22 Alexander D, Schafer F, Olbrich M, Friedrich B, Buhring HJ, Hoffmann J, Reinert S: MSCA-1/TNAP Selection of Human Jaw Periosteal Cells Improves their Mineralization Capacity. Cell Physiol Biochem 2010;26:10731080.

23 Sobiesiak M, Sivasubramaniyan K, Hermann C, Tan C, Orgel M, Treml S, Cerabona F, de ZP, Ochs U, Muller CA, Gargett CE, Kalbacher H, Buhring HJ: The mesenchymal stem cell antigen MSCA-1 is identical to tissue non-specific alkaline phosphatase. Stem Cells Dev 2010;19:669-677.

24 Wu LA, Feng J, Wang L, Mu YD, Baker A, Donly KJ, Harris SE, MacDougall M, Chen S: Development and characterization of a mouse floxed Bmp2 osteoblast cell line that retains osteoblast genotype and phenotype. Cell Tissue Res 2011;343:545-558.

25 Crisan M, Corselli M, Chen WC, Peault B: Perivascular cells for regenerative medicine. J Cell Mol Med 2012;16:2851-2860.

26 Lv FJ, Tuan RS, Cheung KM, Leung VY: The surface markers and identity of human mesenchymal stem cells. Stem Cells 2014.

27 Crisan M, Yap S, Casteilla L, Chen CW, Corselli M, Park TS, Andriolo G, Sun B, Zheng B, Zhang L, Norotte C, Teng PN, Traas J, Schugar R, Deasy BM, Badylak S, Buhring HJ, Giacobino JP, Lazzari L, Huard J, Peault B: A perivascular origin for mesenchymal stem cells in multiple human organs. Cell Stem Cell 2008;3:301-313.

28 Allt G, Lawrenson JG: Pericytes: cell biology and pathology. Cells Tissues Organs 2001;169:1-11. 